\title{
Pet Şişe Şişirme Makinelerinde Fırın Optimizasyonu ${ }^{* *}$
}

\author{
Burcu Bayam $^{1 * *}$, Zeki Oralhan ${ }^{2}$ \\ ${ }^{1}$ Makro Makina, Otomasyon Bölümü, Kayseri, Türkiye (ORCID: 0000-0002-7476-6469) \\ 2 Nuh Naci Yazgan Üniversitesi, Mühendislik Fakültesi, Elektrik Elektronik Bölümü, Kayseri, Türkiye (ORCID: 0000-0003-2841-6115)
}

(Konferans Tarihi: 5-7 Mart 2020)

(DOI: 10.31590/ejosat.araconf64)

ATIF/REFERENCE: Bayam, B., \& Oralhan, Z. (2020). Pet Şişe Şişirme Makinelerinde Fırın Optimizasyonu. Avrupa Bilim ve Teknoloji Dergisi, (Özel Sayı), 494-504.

\section{Öz}

Bu çalışma, Pet Şişe Makinesi üreticilerinin ve son kullanıcılarının bilgilerine danışılarak; Türkiye'de sınırlı sayıda olan Pet Şişe Şişirme makinalarında yer alan firınlar üzerine yapılmıştır. Preformun, makineye girmesinden itibaren kendi ekseni etrafında hareket etmesi ile firın bölümlerinden geçirilerek yeterli ısıya ulaşmasından sonra, şişirme ünitesinde 40 bar yüksek basıncın verilmesiyle şişeler elde edilmektedir. Elde edilen şişelerin kaliteli üretilmesi oldukça önemlidir. Bunun sebebi, Pet Şişe Şişirme makinelerinin devamında, etiketleme, dolum ve paletleme makinelerinin de yer alıyor olmasıdır. Şişelerin kalitesiz olması durumunda hattın tamamı durmaktadır. Şişelerin sağlam olarak üretilmesini sağlamanın en önemli yolu ise, şişenin hammaddesi olan preformların verimli 1sıtılmasıdır. Söz konusu çalışma, prefomların ısıl işlemlerinin daha verimli şekilde uygulanmasını sağlamıştır. Preformun isıl işlemlerinde, firın bölgesinin optimizasyonu sağlamak için; PLC, HMI, ısı kontrolleri, termal 1sı ölçer, termokupl ve termal kamera kullanılmıştır. Termal ısı ölçer, termokupl ve isı kontrollerinden alınan anlık sıcaklık değerleri, referans olarak PLC' ye işlenmiş olup, HMI üzerinden gerekli ayarlamalar kullanıcıya sunulmuştur. PLC' ye alınan referans değerler Codesys tabanlı yazılımda ST dili kullanılarak geliştirilmiştir. Söz konusu çalışmada panel üzerinden anlık değerler gösterilmiştir. Bu veriler kullanılarak, değişken hava şartlarına karşın Pet Şişe Şişirme Makinalarında yer alan infrared lambaların 1sı optimizasyonu sağlanmıştır. Şişelerin hammaddesi olan preformun, geliştirilmiş yazılımla 1sı optimizasyonu sağlanmış firından aldığı 1sılar, termal kamera ile gözlemlenmiş olup; sonuçlar standart sistemde çalışan fırın ile karşılaştırılmıştır. Elde edilen veriler kapsamında, yazılımın preformu olumlu yönde etkilediği ve değişken iklim şartlarından etkilenmeyen, daha kaliteli, maliyeti azaltan şişelerin çıkmasına etken olduğu gözlemlenmiştir.

\section{Oven Optimization In Pet Bottle Blow Molding Machines}

\begin{abstract}
In this study, we have consulted the information of Pet Bottle Machine manufacturers and end users; Located in a limited number of Pet Bottle Blowing Machines in Turkey has been conducted on ovens. After the preform moves around its axis since it enters the machine and reaches the required heat by passing through the oven sections, bottles are obtained by giving 40 bar high pressure in the blowing unit. The quality of the obtained bottles is very important. The reason for this is that the labeling, filling and palletizing machines are also included in the continuation of Pet Bottle Blowing Machines. If the bottles are of poor quality, the entire line stops. The most important way to ensure that the bottles are produced in a robust manner is the efficient heating of the preforms, the raw material of the bottle. This study provided more efficient application of heat treatments of prefoms. In the heat treatment of the preform, to optimize the oven zone; PLC, HMI, temperature controls, thermal heat meter, thermocupl and thermal camera are used.
\end{abstract}

\footnotetext{
* Bu makale International Conference on Access to Recent Advances in Engineering and Digitalization (ARACONF 2020) de sunulmuştur.
}

** Sorumlu Yazar: Makro Makina, Otomasyon Bölümü, Kayseri, Türkiye 
The instantaneous temperature values obtained from the thermal heat meter, thermocupl and temperature controls are processed to the PLC as a reference and necessary adjustments are made available to the user via HMI.

The reference values imported to PLC were developed using ST language in Codesys based software. In this study, instant values are shown on the panel. By using these data, heat optimization of infrared lamps in Pet Bottle Blow Molding Machines despite variable weather conditions is provided.

The heat taken from the oven, the preform which is the raw material of the bottle, which has been optimized by the software, is observed with the thermal camera; The results were compared with the standard oven. In the context of the data obtained, it was observed that the software positively affected the preform and caused the production of bottles of better quality and cost-effective which are not affected by the changing climate conditions.

Keywords: Heat Optimization, Pet Bottle Machine, Preform, Oven Optimization, Oven Control

\section{Giriş}

Günlük hayatımızda tüketilen sıvı veya toz ürünlerin paketleme, ambalajlama, depolama ve nakliyesinde genellikle plastik şişe, kutu, kavanoz ve variller kullanılmaktadır. Çeşitli plastik hammaddeleri (PET, PBT, PP, PVC vb.) 1sıtıp plastikleştiren, bunları uygun bir kalıp içerisinde üfleme metoduyla şişirerek içi boş plastik kapları üreten makinelere şişirme makineleri denir (MEB,2012).

Türkiye'de sınırlı sayıda olan Pet Şişe Şişirme makinaları, yurt dışında da sınırlı sayıda üretici firma tarafından yapılmaktadır. Makinalarda, görsel tasarımla birlikte mekanizmalarında da daha ileriye taşıyacak yenilikçi çalışmalar yapılıyor olması; hızla ilerleyen teknolojilerin yakından takip ediliyor ve uygulanıyor olması, kullanılan elektronik malzemelerin global markalar olması, günümüz rekabet şartlarında makine üreticileri için en belirgin avantajlardır. Söz konusu çalışma ile Pet Şişirme Makinesi teknolojik olarak geliştirilmiş olacaktır. Mevcuttaki tüm pet şişirme makinalarında şişenin hammaddesi olan preformun ısıl işlemleri firın ünitesinde gerçekleşmektedir. Fırın ünitelerinde ise bu 1sınmayı sağlayan özel infrared lambalar yer almaktadır. Preforma uygulanacak olan 1sıl işlemlerin kalitesi; şişenin sağlamlığını artırırken, olası şişe patlama kazalarını, ürün zayi olmasını azaltmaktadır. Bahsedilen ısıl işlem prosesi ise; operatör tarafından insan gözlemlerine dayanarak yapılırken, değişken hava şartları optimizasyonu son derece olumsuz etkileyebilmektedir. Her şişe makinesi operatörünün gözlemlerinin, doğruluk oranı aynı olamayacağı için böyle bir araştırmaya başvurulmuştur.

Optimizasyon, karmaşıklık içerisinde en uygun çözüme ulaştıran sistemler bütünüdür. Fırın optimizasyonu olan bir sistemle olmayan sistemi karşılaştırılması Tablo 1' de yer almaktadır.

\section{Tablo 1. Optimizasyon Olan Fırın Ünitesi İle Standart Çalışan Fırın Ünitesinin Karşılaştırılması}

\begin{tabular}{|c|c|}
\hline Optimizasyon Uygulanan Fırın Ünitesi & Standart Çalışan Fırın Ünitesi \\
\hline $\begin{array}{l}\text { - İklim şartları değişsse bile kullanıcının belirtmiş } \\
\text { olduğu sıcaklık değerine kendisini sabitler. }\end{array}$ & $\begin{array}{l}\text { - İklim şartlarının değişme durumuna karşı, makine başında } \\
\text { sürekli bir operatörünün yer alıp sicaklık değerlerini } \\
\text { değiştirerek ortalama değerini bulması gerekir. }\end{array}$ \\
\hline $\begin{array}{l}\text { - Makine başında sürekli bir operatör beklemesine } \\
\text { gerek duyulmaz. }\end{array}$ & - Makine başında sürekli bir operatör beklemelidir. \\
\hline - Sicaklık değerini özel yazılan blok belirler. & - $\quad$ Sicaklık değerini operatör gözlemleri belirler. \\
\hline $\begin{array}{l}\text { - Isıyı güzel alan prefom çıkma olasılığı çok } \\
\text { yüksektir. Böylelikle preformlardan kaliteli şişe } \\
\text { elde edilir. }\end{array}$ & $\begin{array}{l}\text { - Isıyı verimli alamayan preform çıkma olasılığı çok yüksektir. } \\
\text { Kalitesiz ve hattın işleyini bozan şişeler elde edilmektedir. }\end{array}$ \\
\hline
\end{tabular}

Literatürde yapılan araştırmalarda pet şişirme makinelerinde fırın optimizasyonu ile ilgili çalışmalara pek rastlanılmamıştır. Avunduk (Avunduk, 2019), pet şişirme makinelerinde yalın altı sigma yöntemi ile iyileştirme süreci, (Brandau, 2019) pet şişe şişirme makinelerinin donanımı, (Büyükyıldız, 2016) plc ile cam temperleme fırını otomasyonunu, (Usalan, 2005) endüstriyel tip fırınlarda PID kontrol üzerine çalışmalarda yer almışlardır.

Söz konusu çalışmada ise; PLC (Programlanabilir Lojik Kontrolör) yazılımın, termal kamera ve özel 1S1 kontrol cihazları kullanılarak FBD tabanında ST dilinde geliştirilmesi ile, makinenin yer aldığı ülke ve şehir şartlarından bağımsız, kaliteli şişelerin elde edilmesi ve maliyetin düşürülmesine katkı sağlaması hedeflenmektedir. Bu çalışmada ikinci bölümde PLC, programlama dili, kullanılan özel cihazlar ve HMI' dan bahsedilmiştir. Üçüncü bölümde deneysel çalışma incelenmiş olup, dördüncü bölümde ise sinyal grafikleri ve görsellerle beraber sonuçların değerlendirilmesi yapılmıştır. 


\section{Materyal ve Metot}

\subsection{Programlanabilir Lojik Kontrolör (PIc)}

Programlanabilir denetleyiciler; probleme bağlı olmaksızın, seri olarak üretilmiş, üniversal kumanda ve kontrol elemanlaridır (Eason, Noble, ve Sneddon, 1955)

PLC’ler endüstri alanlarında kullanılmak üzere tasarlanmıştır.

Sayısal prensiplere göre, programlama üzerine yazılan programları gerçekleştiren, sistem ya da sistem gruplarını, giriş ya da çıkış kartlarını denetleyen, içinde barındırdığı zamanlama, sayma, saklama ve aritmetik işlem fonksiyonları ile genel kontrol sağlayan elektronik bir cihazdır (Arslan, 2018).

Şekil 1'deki gibi PLC temel olarak, mikro işlemci yani CPU, sinyallerin işlendiği giriş bölümü ve de kumanda edilecek elemanların bağlandığg çıkış bölümünden oluşmaktadır.

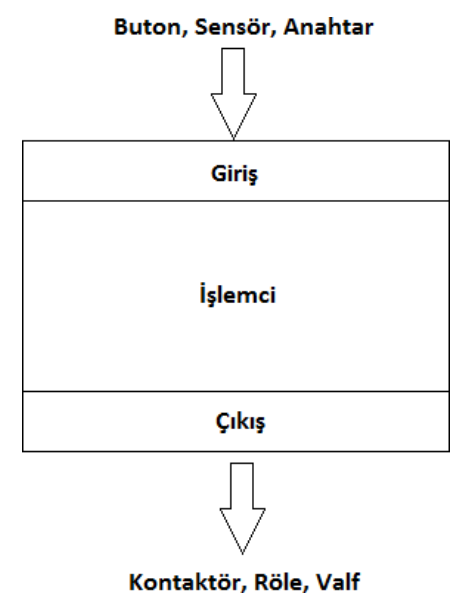

Şekil 1. PLC'nin Yapısı

Çalışmada LENZE L-FORCE CONTROLLER 3231C serisi PLC kullanılmıştır. Cihazın çevrim süresi 1ms olup, ethernet ve ethercat ile aynı anda senkron çalışma imkanı sağlamıştır. Aynı zamanda codeysy tabanlı olması avantaj sağlamıştır.

Codesys programlama dili sSmart tarafından yazılmış ve 1995 yılında endüstrinin kullanımına sunulmuştur. PLC programlama ve endüstriyel PC sistemlerinde kullanılan yazılım sadece bir markaya ait değildir. Codesys tabanlı olması ile beraber tercih edilen yazılım dili ST(Structured Text) olmuştur. ST, Visualbasic ve C++ dillerinin birleşimi gibidir (Arslan, 2018).

\subsubsection{ST ( structured text) Kodlama İle Yazılım}

PLC programlama kodlarla yapılmaktadır. Kodlama dili program dilinde Visualbasic ve C++dilinin birleşimi gibidir (Arslan, 2018). Şekil 2’ de örnek kodlama yer almaktadır.

Örnek Kod:

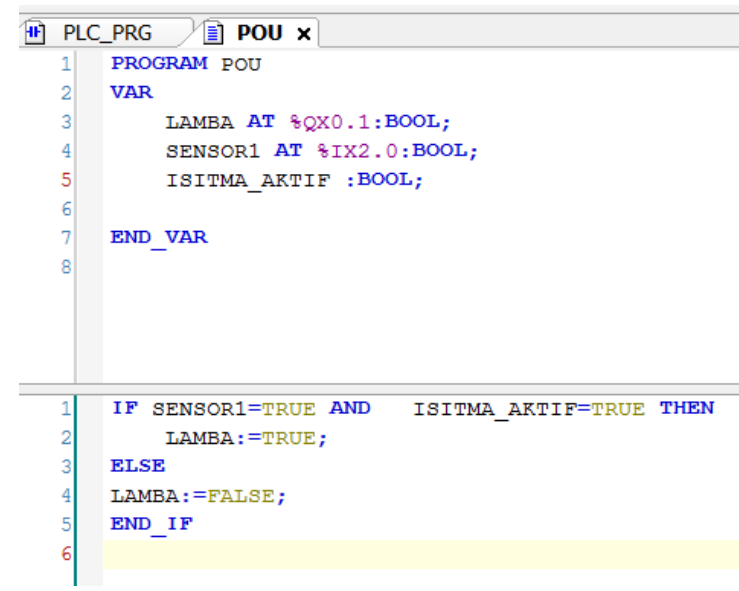

Şekil 2. ST Kodlama Örneği

Örnek Kod Açıklaması: Sistemde tag ismi lamba olarak tanımlanan bir dijital çıkış yer almaktadır. Sistemde modülün birinci çıkışına montajı sağlanmış. 
Aynı zamanda sensör1 isimli dijital girişin 2. modülünün birinci girişine monte edilmiş sensör yer almaktadır. Çalışma esnasında eğer sensör1 isimli algılayıcı TRUE sinyalini gönderirse ve ssıtma aktif datası aktif olursa lamba çalışacaktır.

\subsubsection{FBD ( function block diagram) Kodlama İle Yazılım}

Genelde kapılar ve blok diyagram mantığı ile yazılan programlama türüdür (Arslan, 2018).

Örnek Kod: ST (structured text) kodlamasında yer alan örneğin FBD dilinde yazılımı şekil 3’ de yer almaktadır.

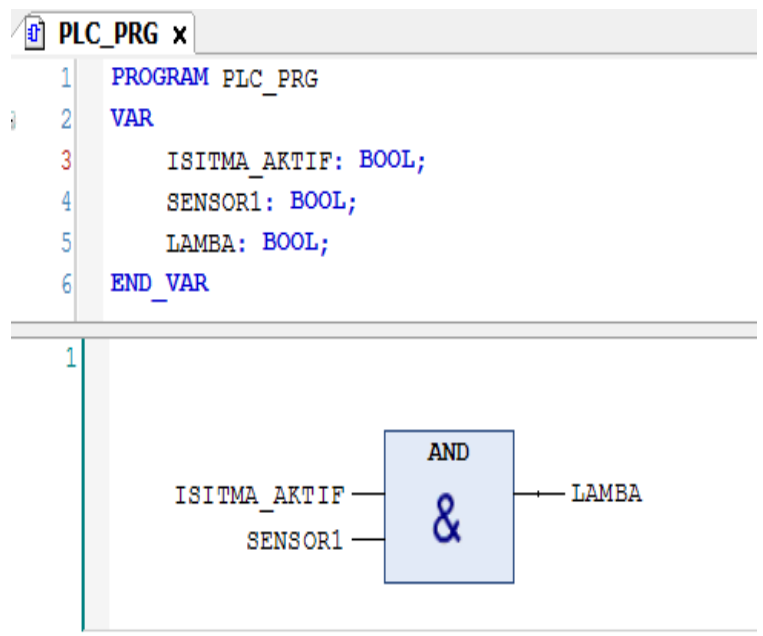

Şekil 3. FBD Kodlama Örneği

\subsection{Termal Kamera}

Termal kamera, görüntüleme yöntemi olarak gözle görülmeyen IR enerjiyi (1sıyı) esas alan ve görüntünün genel yapısını IR enerjiyi göre oluşmuş renkler ve şekillerin belirlendiği görüntüleme sistemidir (Gülgör, 2004).Termal kameralar; kullanım alanlarına göre farklı çeşitleri olan cihazlardır. Çalışan ve Türkoğlu (Çalışan ve Türkoğlu, 2011), çalışmalarında elektrik, elektromekanik, mekanik ve sağlık gibi farklı alanlarda termal kamera uygulamaları yapmışlardır.

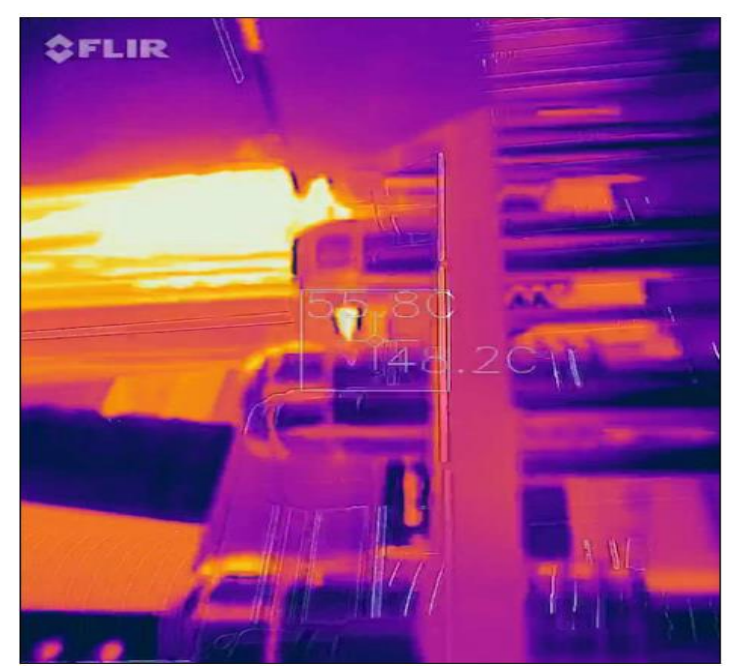

Şekil 4. Sicaklık Değerlerinin Takibi

Söz konusu çalışmada uzaktan ölçüm yapmamızı sağlayan FLIR marka cihaz kullanılmıştır. Fırın bölgesinde çalışma öncesinde ve sonrasında Şekil 4' deki gibi sabit bir sıcaklık değeri tespiti yapılmıştır.

\subsection{Termal Isı Ölçer Sensörler}

Termal ısı ölçer sensörler, materyalin belirli bir noktasından okuduğu sıcaklık birimini, mA, mV gibi aralıklarda kullanıcıya çıkış vermeyi sağlayan Şekil 5' de görülen özel cihazlardır. 


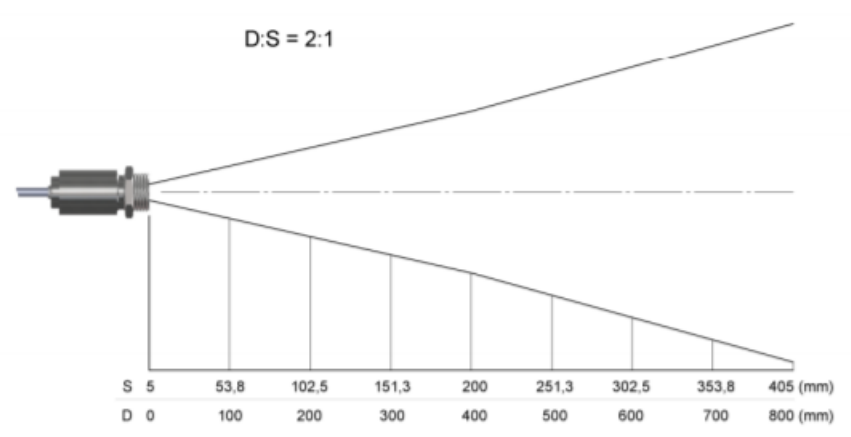

Şekil 5. Termal Analog Isl Ölçer Sensör (Optris, 2015)

Çalışmamız esnasında OPTRIS marka CT LT serisi özel cihaz, firın çıkışında preformların noktasal 1Sı ölçümlerinde kullanılmıştır. 4-20 mA aralı̆̆ında gönderdiği çıkış sinyali, PLC' de geliştirilmiş olan özel bloğun içerisine işlenmiştir.

\subsection{Termokupl Sensör}

Termokupl, iki farklı alaşımın ucunun kaynaklanması ile oluşan basit bir sıcaklık ölçü elemanıdır (Elimko, 2016).

Kaynak noktası sıcak nokta, diğer açık iki uç soğuk nokta (veya referans noktası) olarak anılır. Termokupl olayı sıcak nokta ile soğuk nokta arasındaki sıcaklık farkından doğar. Bu sıcaklık farkına orantılı, soğuk nokta uçlarında mV mertebesinde gerilim üretilir. Şekil 6' da ölçüm bölgesinin şekli gözükmektedir.

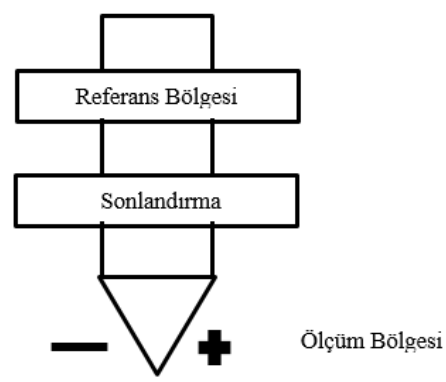

Şekil 6. Termokupl Ölçüm Bölgesi

Kullanım alanlarına göre farklı çeşitleri olmakta olup, yapısında kullanılan malzeme türlerine göre çeşitleri bulunmaktadır. Tablo 2' de yer alan tabloda termocupl çeşitleri yer almaktadır.

Tablo 2. Termokupl Çeşitleri (Jumo, 2008)

\begin{tabular}{|l|l|l|l|l|}
\hline Termokupl & Maksimum Sicaklık & Üst Limit & Pozitif Kenar & Negatif Kenar \\
\hline Fe-Con & $750{ }^{\circ} \mathrm{C}$ & $1200^{\circ} \mathrm{C}$ & Siyah & Beyaz \\
Cu-Con & $350^{\circ} \mathrm{C}$ & $400^{\circ} \mathrm{C}$ & Kahverengi & Beyaz \\
NiCr-Ni & $1200{ }^{\circ} \mathrm{C}$ & $1370^{\circ} \mathrm{C}$ & Yeşil & Beyaz \\
NiCr-Con & $900^{\circ} \mathrm{C}$ & $1000^{\circ} \mathrm{C}$ & Mor & Beyaz \\
NiCrSi-NiSi & $1200^{\circ} \mathrm{C}$ & $1300^{\circ} \mathrm{C}$ & Leylak & Beyaz \\
Pt10Rh-Pt & $1600{ }^{\circ} \mathrm{C}$ & $1540^{\circ} \mathrm{C}$ & Turuncu & Beyaz \\
Pt13Rh-Pt & $1600{ }^{\circ} \mathrm{C}$ & $1760^{\circ} \mathrm{C}$ & Turuncu & Beyaz \\
Pt30Rh-Pt16Rh & $1700^{\circ} \mathrm{C}$ & $1820^{\circ} \mathrm{C}$ & Veri yok & Beyaz \\
\hline
\end{tabular}

Maksimum sıcaklık belirtilen tolerans için limiti göstermektedir. "üst limit" altındaki değer, termal gerilimin standart belirtmeler ile kapsandığı sıcaklık limitidir. Tablo 2' de gösterilen termokupllarda ilk kenar her zaman pozitif olandır. Renk kodları termokuplın kendisi ve kompanzasyon kablolarının her ikisi için de geçerlidir (Jumo, 2008).

Fe-Con yapısındaki $\mathrm{J}$ tipi termokupl, $0-1200^{\circ} \mathrm{C}$ aralığında daha doğrusal verilere sahip olması sebebiyle çalı̧mamızda tercih edilmiştir. Şekil 7' de firın içerisinde yerleşim şekli yer almaktadır. 


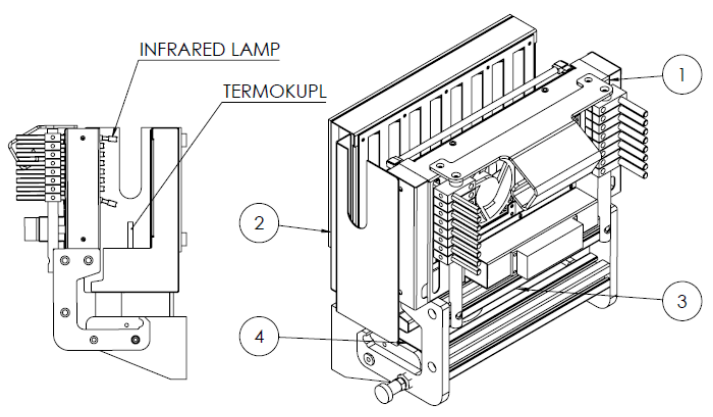

Şekil 7. Termokupl Furın Yerleşimi

Fırın içerisindeki actual olarak termokupl ile alınan değerler, geliştirilen blok içerisinde ısı kontrolünün sağlanmasında ana veri olarak kullanılmıştır.

\subsection{HMI (Human-Machine Interface)}

Teknolojinin ilerlemesi ile otomasyon sektörü daha çok değer kazanmakta ve teknolojiye yetişmek adına daha fazla yenilik_üretmeye çalışmaktadır. HMI Sistemler de bu üretim aşamalarının temelidir. Açılımı "Human-Machine Interface" olarak bilinen HMI terimi, "İnsan-Makine Arayüzü" anlamına gelen, "dokunmatik panel”, "touch panel”, "operatör panel” gibi isimler ile "Endüstriyel Otomasyon" sektörünün gözdesi olmuştur. Erişilebilir bir bilgi iç̧erisinde karmaşık olan verileri çevirerek, operatör üretim sürecini kontrol etmektedir (Bulut, 2015). Yapılan çalışmada LENZE p300 model HMI kullanılmış olup, ethercat üzerinden PLC ile haberleştirilmiştir (Lenze, 2016).

Panel üzerinde; infrared lambalara gönderilen referans değerlerini, firın ve preform sıcaklığının actual değerlerini gözlemleyebilmek için özel sayfalar oluşturulmuştur.

\section{Araștırma Sonuçları ve Tartışma}

\subsection{Deneysel Çalışma}

Şekil 8'de optimizasyon işleminde kullanılacak malzemelerin elektrik şeması yer almaktadır. PLC, 1sı kontrolörü ile ethercat üzerinden haberleşmiş olup; HMI ise sisteme ethernet üzerinden adapte edilmiştir. Ethernet ve ethercat'in aynı anda senkron çalışmasıyla birlikte yazılım oluşturulmaya başlanmıştır.

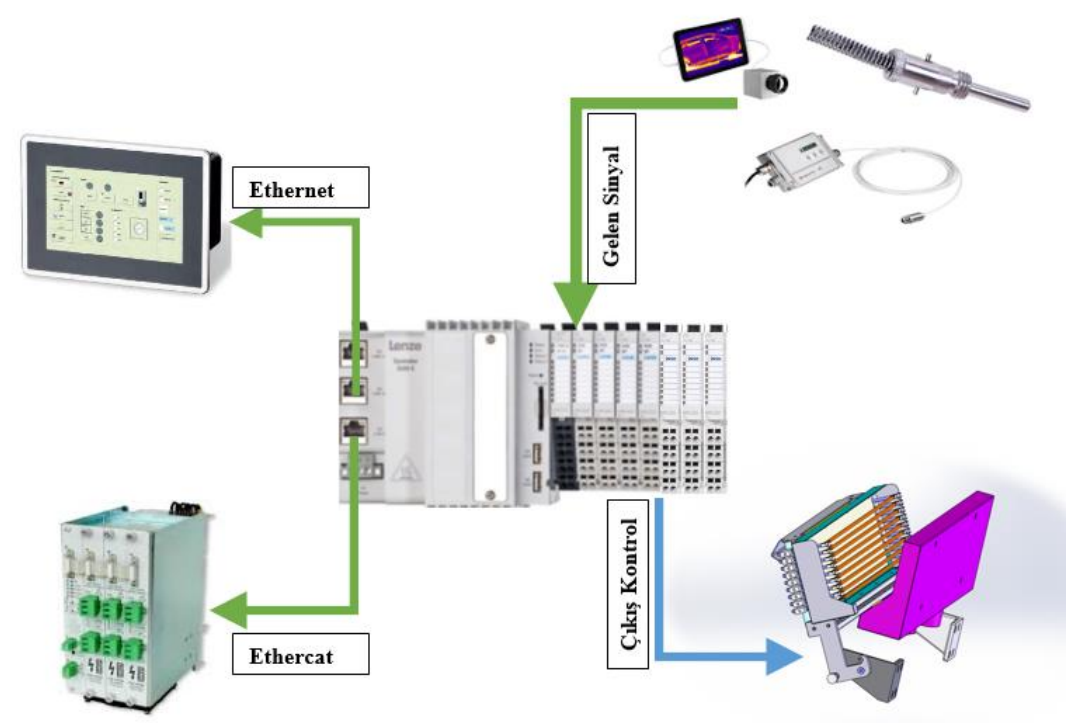

Şekil 8. Network Hattı 
Fırın ünitesi içerisinde yer alan Termokupl için ayrı, 1sı ölçer sensör için ayrı bir analog modül PLC' nin yan tarafina akuple edilerek sisteme dahil edilmiştir. Söz konusu iki ayrı sıcaklık ölçer cihazların anlık değerleri; değişken hava şartlarına karşın, optimizasyon sisteminin devreye girmesiyle beraber analog giriş modülleri aracılığıyla PLC' ye aktarılmıştır.

HMI üzerinde kullanıcı için lambalara referans değerlerin gönderilmesi ve preformun sıcaklıkları gösterilecektir. Operatörün panel üzerinden gireceği proses ayarları ile, yazılımın aktif hala getirilmesi sayesinde sağlıklı şişe çıkmasında önemi olan 1sıl işlem kendisini otomatik olarak ayarlayacaktır.

\subsubsection{Pet Şişe Şişirme Makinasının Tasarlanan Panel Sayfası}

Şişelerin hammaddesi olan preform, makineye girmesinden itibaren firınlar içerisinde yer alan infrared lambalar tarafindan belli bir sıcaklığa maruz kalırken, hava şartlarından da etkilenmektedir.

HMI' da, lambaların her birine analog referans değerler gönderilmek üzere girişler ayarlanmıştır. İklimsel değişikliği test edebilmek adına, sisteme soğutma fanları ilave edilmiştir. Havanın soğuması veya sıcaklığın artması durumu bu fanların ayarları baz alınarak teste dahil edilmiştir.

Sistemde preform 1sısı için alt ve üst limit sıcaklıkları belirlenmiştir. Bu sayede alt limit sıcaklığı sağlanmadığı sürece preform fırınlara geçiş yapamamıştır, üst limitini olası aşılma durumunda ise; şişirme bölümüne gönderilmeden şişeler firın çıkışında pasif hale getirilmiştir. Yapılan bu uygulama makinenin daha sağlıklı üretim yapmasına etken olmuştur.

Ekranda yer verilmiş olan, firın set sıcaklık değeri ile de fırın optimizasyonu sağlamak amaçlanmıştır. Şekil 9'da panel sayfasının görseli yer almaktadır.

\begin{tabular}{|c|c|}
\hline Servis Havası [6-8] & 8 bar \\
\hline Körìk Basınç & 0 bar \\
\hline Yuksek Basınç & 0 bar \\
\hline Preform Sicaklığı & $20^{\circ} \mathrm{C}$ \\
\hline Fırın Sıcaklığı & $14{ }^{\circ} \mathrm{C}$ \\
\hline Uretim Sirresi & $0 \mathrm{~ms}$ \\
\hline Uretim Kapasitesi & $3001 \S / S$ \\
\hline Uretim Adedi & 0 Adet \\
\hline \multicolumn{2}{|l|}{ RESET } \\
\hline \multicolumn{2}{|l|}{ Sicaklık Setleri } \\
\hline Preform Sicaklik Ust Limit & $100^{\circ} \mathrm{C}$ \\
\hline Preform sicaklik alt limit & $50^{\circ} \mathrm{C}$ \\
\hline Fırın Sıcaklık Set Değeri & $35^{\circ} \mathrm{C}$ \\
\hline
\end{tabular}

\section{Şekil 9. Panel Sayfası}

Söz konusu çalışma 4 ayrı firının olduğu makine sistemi üzerinde geliştirilmiş olup; her firında 8 adet infrared lamba kullanılmıştır.

\subsubsection{Firın Optimizasyonu}

Usalan [5], endüstriyel tip firında PID kontrolü çalışması yapmış olup, kullanmış olduğu yazılım bloğunun neticesinde sağlıklı veriler elde etmiştir.

Şekil 10’ da görülen geliştirilmiş yazılım bloğuyla, çalışma esnasında firın içerisinde soğutma fanlarına yapılan ayar, iklimsel değişiklik olarak değerlendirilmiş olup; firın kendi optimizasyonunu, yani 1s1 optimizasyonunu otomatik sağlamıştır. Değişen ortam sıcaklığına göre yazılan özel blok, ekrandan kullanıcının gireceği “Fırın Set Değeri” ne kendini sabitleme işlemini gerçekleştirmiş̧tir. İçerisinde kullanılan katsayılarla, firının sıcaklı̆ğında set değerini aşan bir durumda azaltan katsayılar devreye girerken, limitin altında kalan $1 \mathrm{sı}$ değerlerinde ise artıcı katsayılar devreye girmiştir. 


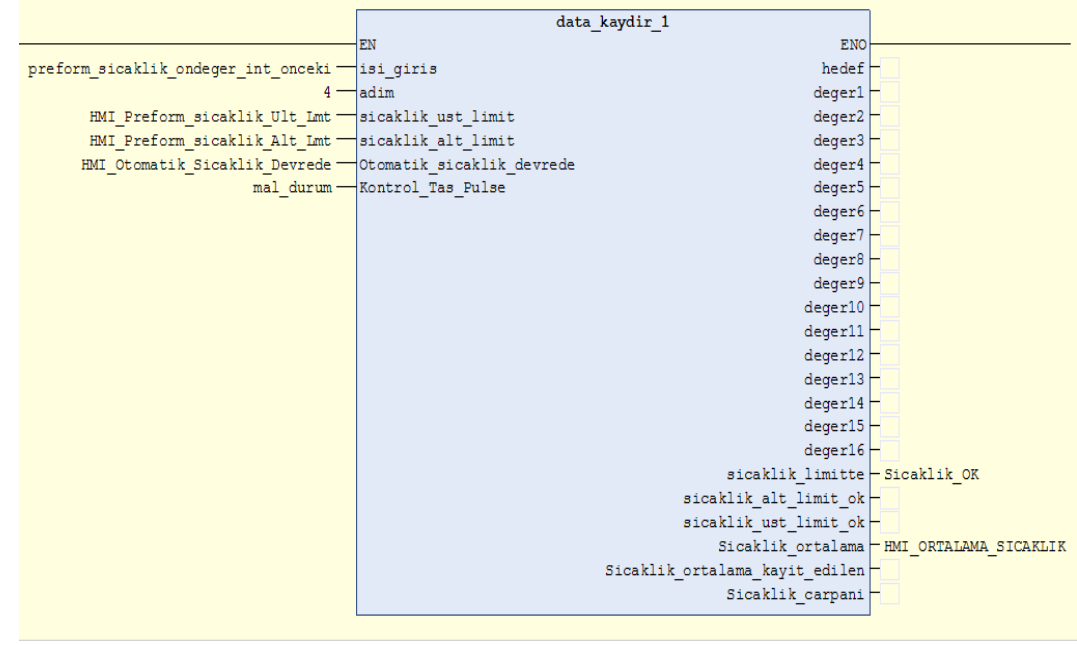

Şekil 10. Optimizasyon Blok

\subsubsection{Optimizasyon Blok Yazılım}

Çalışmanın yapılmış olduğu söz konusu makinede, yaklaşık 130 adet preform taşıyıcı mekanizma olup, hem makine ekseni etrafinda hem de kendi eksenleri etrafinda dönme hareketini yapmaktadırlar. Fırınların tamamını aktif hale getirip, otomatik 1s1 optimizasyonu Şekil 10' da yer alan optimizasyon blok üzerinden "HMI_Otomatik_Sıcaklık_Devrede" girişine aktif etme sinyali gönderilmesi ile çalışma başlatılmıştır.

FBD yazılım yerine blok olarak tanımlanan "data_kaydir_1" isimli yazılım ST dilinde geliştirilmiş "array” tipinde bloktur. Şekil 11' de blok tasarım yazılımının bir bölümü yer almaktadır.

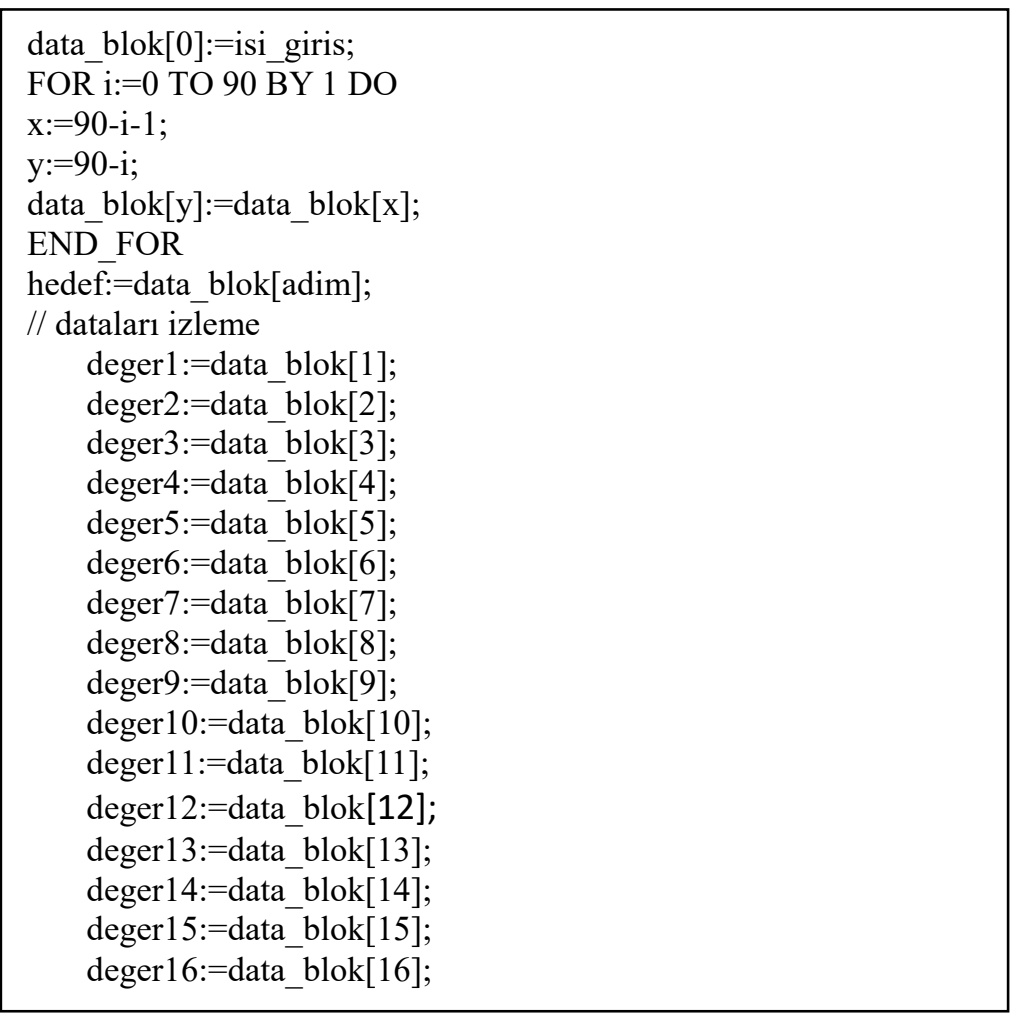

Şekil 11. Optimizasyon Blok Yazılım Giriş Bölümü 


\section{Sonuçlar}

Yazılımın test aşamasında fan değerleri belirli bir seviyede tutulmuştur. Operatörün, ekrandan belirlemiş olduğu "Fırın Set" değerini, optimizasyonsuz olarak kendi ayarlamalarıyla elde etmesindeki çalı̧̧ma grafiğinin dalgalı ve kararsız olduğu gözlemlenmiştir. Şekil 12' de kararsız çalışan yapının grafiğine yer verilmiştir. Tablo 3' de grafikte kullanılan tagların renk kodlamaları belirtilmiştir.

\section{Tablo 3. Grafikte Baz Alinan Taglarin Renkleri}

\begin{tabular}{|l|l|}
\hline Yazılımda Kullanılan Tag & Grafikte Kullanılan Renk \\
\hline Sıcaklıkta Fark Var & Koyu Pembe \\
\hline Sıcaklık Çarpanı & Pembe \\
\hline Otomatik Sıcaklık Çarpanı & Turuncu \\
\hline Lamba Referans & Lacivert \\
\hline
\end{tabular}

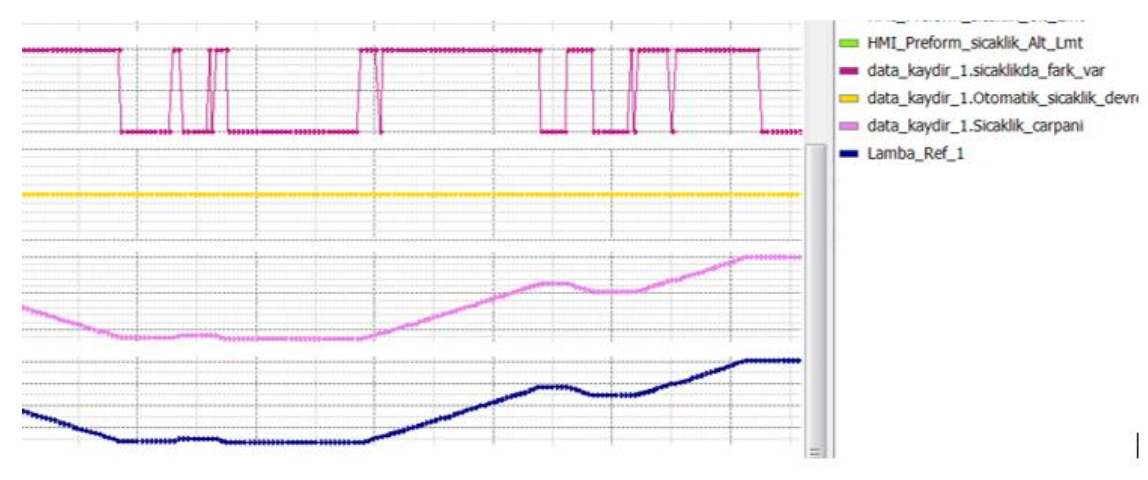

\section{Şekil 12. Optimizasyonun Kullanılmadĭ̆ında Elde Edilen Kararsız Çalı̧̧ma Grafiği}

Bloğun çalışma şartlarının daha iyi gözlemlenmesi amacıyla, ortam sıcaklığı fanların değerlerine müdehale edilerek değiştirilmiş̧tir. Operatör, aynı lamba referans değerlerinde, HMI_Otomatik_Is__Kontrol tag bilgisini aktif hale getirmesiyle sistem kendisini, yazılımda tanımlanan katsayı çarpanıyla belirli bir süre sonunda operatörün ilk çalışmada belirlemiş olduğu set değerine sabitlemiştir. Şekil 13' de optimizasyon sisteminin aktif olması durumunda elde edilen grafiğge yer verilmiştir.

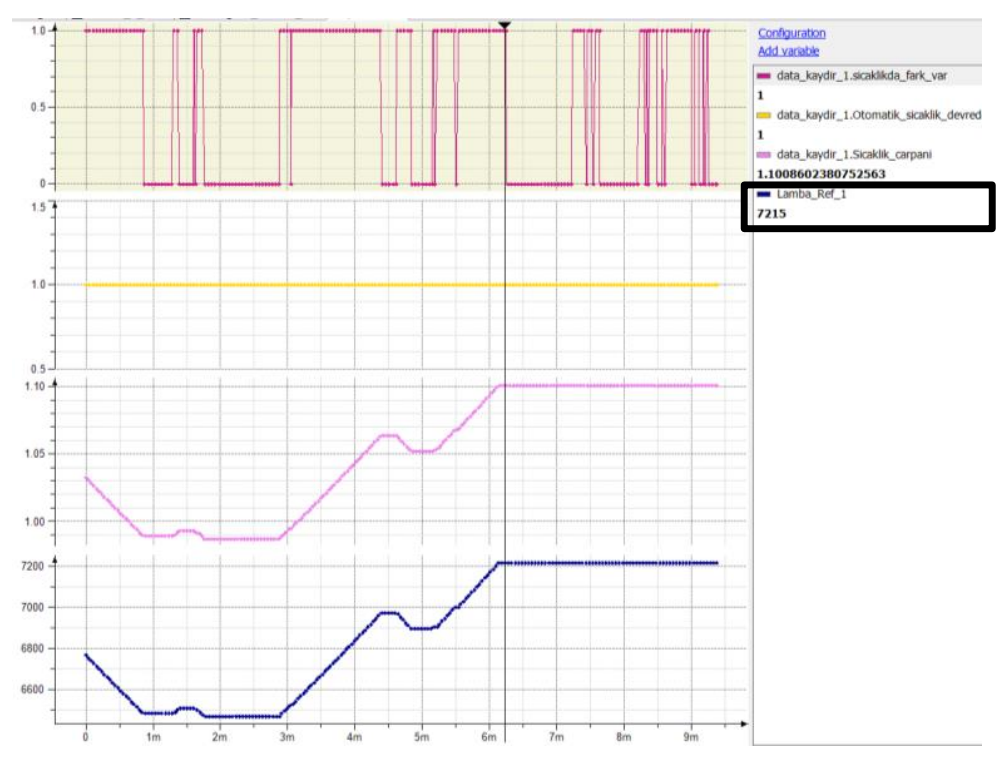

Şekil 13. Optimizasyon Sistemi Aktif Edildiğinde Elde Edilen Kararlı Grafik

Data blok kendi içerisinde ST dilinde tanımlanmış yazılımda, otomatik sıcaklık aktif olduğu an preform set sıcaklığını hesaplayıp kendi içerisine kaydetmektedir. Preform taşıyıcıların hareketi ile de array blok tüm taşıyıcıların sıcaklık değerlerini kendi içerisine 
çekerek, preform set sıcaklığını hesaplamıştır. İklim şartları değiştiği an, blok sıcaklıkta fark var bilgisini sisteme yansıtarak dengenin kurulmasını ve lambaların sıcaklarının firın sıcaklığına sabitlemesini sağlamıştır.

Fırın Set Sıcaklığının $44{ }^{\circ} \mathrm{C}$ olması şartları altında, optimizasyonun aktif edildiği çalışmada; lamba referansı gelen "sıcaklıkta fark var" bilgisine göre belli bir süre içerisinde kendisini otomatik ayarlamış olup 7215 değerinde sabitlemiştir.

Lambaların referans değerleri için kullanılan analog modüllerde ölçüm aralı̆̆ı 16384dec olarak belirlenmiştir.

Bu hesaba göre ;

$7215 / 163.84=44{ }^{\circ} \mathrm{C}$ ' ye lambanın referansı ayarlanmıştır. Elde edilen veriler değerlendirildiğinde, belirlenen firın set sıcaklığına lamba değerlerinin kendini stabilize ettiği sonucuna varılmıştır.

Şekil 13 ve 14' de optimizasyon yapılan firın ile iklim şartlarına göre optimizasyonunu olmayan firınların termal kamera ölçümleri yer almaktadır. Optimizasyon grafiği ile eş zamanlı yapılan termal ölçümde de $44^{\circ} \mathrm{C}$ değeri ile bloğun sağlıklı çalıştı̆̆ test edilmiştir. Operatörün ilk çalışmasında, sistem aktif değilken elde edilen grafikle beraber yapılan termal ölçümde $55{ }^{\circ} \mathrm{C}$ değeri okunmuştur.

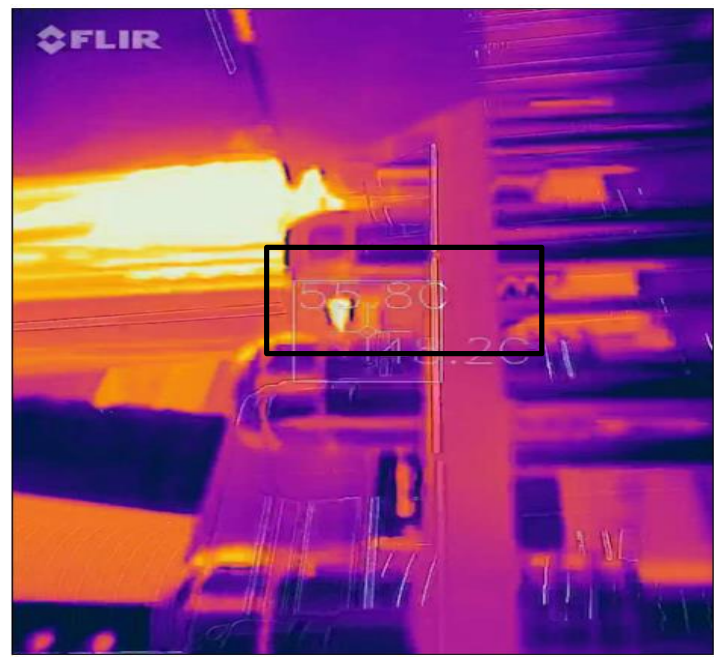

Şekil 14. Optimizasyon Olmayan Firın

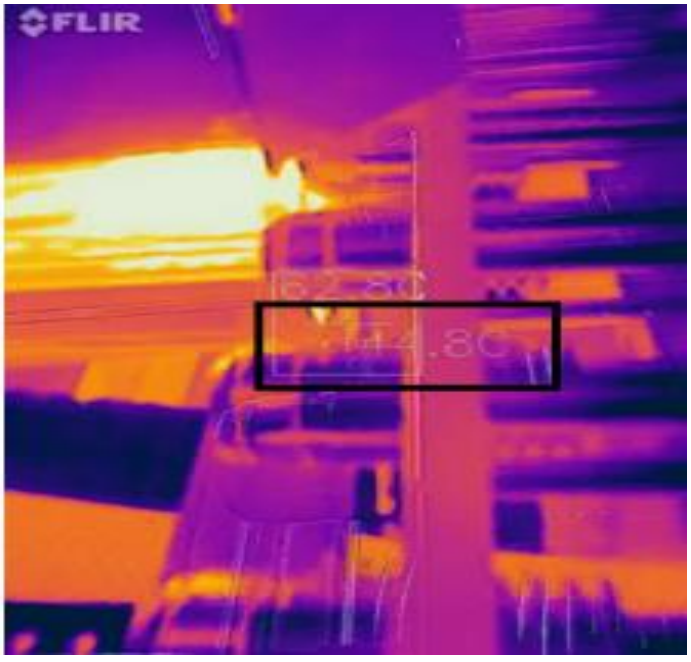

Şekil 15. Optimizasyon Olan Fırın

Şişelerin kalitesinde preform sıcaklığının verimli olarak uygulanması çok önemlidir. Sıcaklığ $55^{\circ} \mathrm{C}$ olan firın ünitesinden çıkan preformlar yanık halde çıkmıştır ki bu istenmeyen bir durumdur.

Makinanın başında en az bir operatörün 1sı kontrolünün ayarı için sürekli bulunması, tamamen kendi gözlemleri üzerine proses ayarlarını yapıyor olması ve de doğru ayarlarının yapılamaması neticesinde; preformun 40 bar havaya maruz kaldığı anda patlaması, şişirme ünitesine dahil olamadan zayi olması veya şişe olarak çıktığında taban kısımlarındaki olası yanma, zayıflık durumlarında üretim hattının devamındaki dolum, etiketleme ve paletleme makinalarındaki tüm işleyişi bozması gibi zararlara sebep olabilmektedir. Bununla birlikte bir makine de normalde \%3 e kadar preform zayiatı kabul edilmektedir. Söz konusu proje ile bunu $\% 1$ in altına düşürülmesi hedeflenmektedir ki; makinenin çalışma esnasında operatöre olan bağımlılığının büyük ölçüde azaltıllacak olması da avantaj olacaktır. Buna göre hesap yapılacak olursa;

1 Ton Preform $=1650 \$$

Test Çalışması Yapılan Makine Üretim $=6000$ şişe/saat

Makine Üretimi( Gün) $=48000$ şişe/gün

Zaiyat $=$ Gün üzerinden $\% 3$ hesabı ile 1440 adet

Ayda 43200 adet zayi olan preform bedeli yaklaşık 6000\$ olacaktır.

Tasarlanan yazılım ile nihai makine kullanıcısının maliyetindeki bu kayıbın büyük ölçüde azaltılacak olması en büyük avantajdır.

Pet Şişe Şişirme makinelerinde, firın içerisindeki sıcaklı̆̆ın optimizasyonu son derece önemlidir. Yapılan çalışmada optimizasyonun olmadığı firında sıcaklık değerlerinin kararsız çalışı̆̆ı ve bunun sonucunda kalitesiz preformların çıktığı gözlemlenmiştir. Optimizasyon olan firındaysa, yazılımda oluşturulan özel blok sıcaklıkta fark var bilgisini üreterek, lambaların kendini operatörün belirlediği set sıcaklığına sabitlediği gözlemlenmiştir. 


\section{Kaynakça}

MEB. (2012). Şişirme Makinelerinde Üretim. Ankara

Avunduk, H. (2019). Yalın altı sigma: bir pet şişe makinesinde süreç iyileştirme uygulaması. Elektronik Sosyal Bilimler Dergisi, 18, 633-653.

Brandau, O. (2019). Stretch Blow Molding. USA: Elsevier

Büyükyıldız, A. (2006). Plc kullanarak cam temperleme firınının otomasyonu. Pamukkale Üniversitesi Mühendislik Bilimleri Dergisi, 13, 247-256.

Usalan, M.A., (2005). Bir endüstriyel firın otomasyonu. Yüksek Lisans Tezi Mart 2015.

Eason, G., Noble, B., Sneddon, I.N. (1955). On certain integrals of Lipschitz-Hankel type involving products of Bessel functions. Phil. Trans. Roy. Soc. London, vol. A247, 529-551.

Arslan, F. (2018). Codesys İle Plc Programlama. İstanbul: Birsen Yayınevi

Gülgör, E.(2004). Termal kamera nedir. 22 Ekim 2019 tarihinde https://www.elektrikport.com/teknik-kutuphane/termal-kamera-nedirmuhendislik-uygulamalari-ve-kullanim-alanlari/11460\#ad-image-0 adresinden erişilmiştir.

Çalışan, M., Türkoğlu, İ. (2011). Termal Kameralar Ve Uygulamaları. Elektrik Elektronik Bilgisayar Sempozyumu'nda sunulan

bildiri. Firat Üniversitesi, Elazı̆̆.

Optris , (2015). Operator's manuel. 22 Ekim 2019 tarihinde https://www.optris.com.tr/compact-series adresinden erişildi.

Elimko, (2016). Termokupllarla ilgili genel bilgiler. $22 \quad$ Ekim $2019 \quad$ tarihinde http://www.elimko.com.tr/files/TermokupllarGenelBilgiler.pdf adresinden erişildi.

Jumo, (2008). Termokuplların yapısı ve kullanımı. 22 Ekim 2019 tarihinde http://www.jumo.com.tr adresinden erişildi.

Bulut, C. (2015). Otomasyon sektörünün geleceği HMI sistemler. 22 Ekim 2019 tarihinde https://www.elektrikport.com/teknikkutuphane/hmi-sistemlerini-yakindan-taniyalim/16489\#ad-image-0 adresinden erişildi.

Lenze, (2016). Hardware Controller 3200C and P300. Germany 